\title{
Architectural Design Criteria for Spacecraft Solar Arrays
}

\author{
Antonio De Luca \\ VEGA Space GmbH \\ Germany
}

\section{Introduction}

Scope of this chapter is to provide design criteria for spacecraft solar arrays at system level. The design a satellite solar array is usually influenced by several constraints; mission profile, chosen attitude, overall spacecraft configuration, mass and sizing requirements, etc.

Moreover, its design has to be harmonised with the chosen solar array power conditioning, in order to optimize mass, dimensions, and also particular constraints coming from EMC and thermal environments.

The chapter is basically composed of the following sections;

1. General description of the current solar cell technologies currently used in space, with particular attention to the triple junction solar cells.

2. Mathematical model of an equivalent solar cell circuit, to be used for performance calculations in a numerical simulation environment.

3. Mathematical description of a simplified thermal model of a solar array in order to analyse solar array performances in orbit.

4. Short definition of cosmic radiation effects.

5. The satellite power budget, starting point for the solar array sizing

6. The impact of the power conditioning architecture on the solar array (electrical operative point, EMC considerations).

7. The configuration of the solar array with respect to the spacecraft.

8. Some design examples for different missions and satellite configurations.

9. Numerical simulations of solar array performances as function of the mission profile (orbit propagation, slew manoeuvres, attitudes of particular interest).

\section{Solar cells for space applications}

Since the beginning of the astronautic era, photovoltaic devices have been considered for the generation of electrical power on board spacecrafts because of their high power output per unit mass, associated with the fundamental advantage of not having moving parts, present, instead, in all the most used electrical power generators for both terrestrial and aeronautical applications (turbines, motors, alternators, etc.). Therefore the PV array is static, does not produce vibrations or noise, and does not need an active cooling. The Russians were the first, in 1958, to launch a satellite powered with silicon solar cells. 
Solar cells for space applications have to be highly efficient, capable to stand thousands of thermal cycles in orbit where the temperature, according to the mission profile may vary from $-150^{\circ} \mathrm{C}$ to more than $120^{\circ} \mathrm{C}$. They have to show a limited degradation during time due to cosmic radiations and Ultraviolet, and they have to resist to the mechanical solicitations mainly linear accelerations and vibrations during launch and orbital manoeuvres, because of these constraints the cells for space are smaller than those for terrestrial applications.

In order to have the highest conversion efficiency, solar cells for space application are developed from mono-crystalline materials. In the past silicon was the most used and the reachable bulk efficiency was not higher than $14 \%$. The advent of GaAs based solar cells in the last decade of the $20^{\text {th }}$ century took the efficiency up to $19 \%$, and nowadays triple junction solar cells show more than $30 \%$.

Figure 1 shows a very simplified structure of triple junction cell.

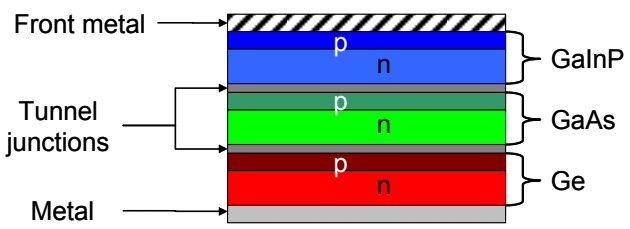

Fig. 1. Triple junction solar cell structure

While figure 2 reports the quantum efficiency for each junction, it can be clearly seen that the increased efficiency is due to wider wavelength coverage of the absorbed radiation.

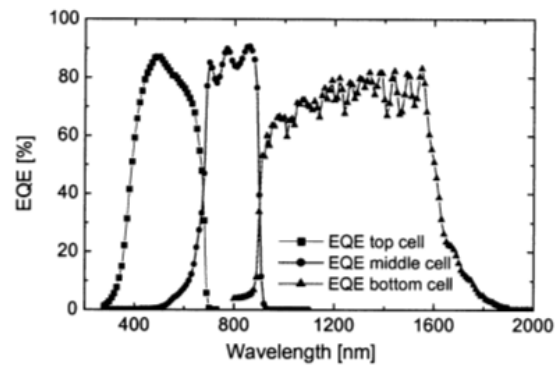

Fig. 2. Equivalent quantum efficiency as function of wavelength

Triple junction GaAs solar cells are populating more and more solar generators worldwide, while manufacturers are actively working on four to six junction cells as a way forward always increasing conversion efficiency. Consequently, there is a need to improve the understanding of the electrical dynamic behaviour of multi-junction based solar array considering that the proper design of solar array regulators requires, among others, a good mastering of the solar section/regulator interface. In order to better understand EMC aspects connected to the chosen regulation philosophy, which will be discussed further, it is worth to have a quick look at the equivalent capacitance present at the output of a triple junction cell. The figure 3 reports the capacitance measured across strings composed of 15 cells. The cells used are produced by AZUR SPACE Solar Power GmbH. It can be observed that at high voltages the capacitance is considerably increased. Such behaviour has to be 
taken into account when the power conditioning architecture is chosen, and the relevant devices designed.

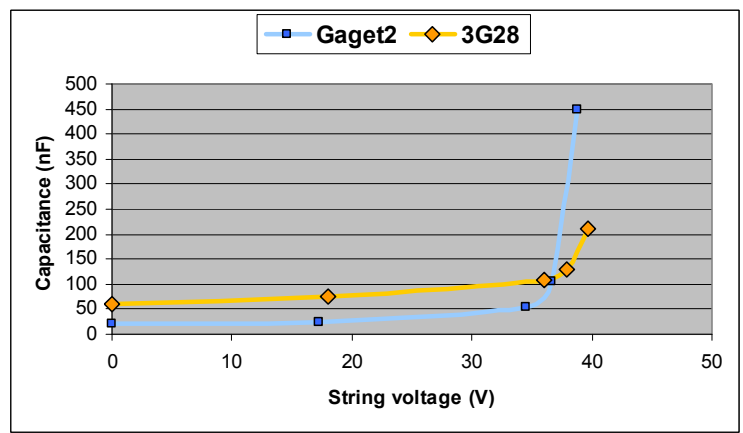

Fig. 3. Capacitance identified for the 15 cells string, Gaget2 and 3G28 (AZUR SPACE products)

\section{Solar cell equivalent circuit}

The mathematical model of a photovoltaic cell has to take into account the following factors capable to influence the solar cell behaviour.

1. Intensity of the incident light.

2. Operative absolute temperature.

3. Degradation by cosmic radiation.

The solar cell model, derived from the Mottet-Sombrin's one, is basically a current generator driven by the value of the voltage applied at its terminal according to the equivalent circuit reported below. Generally speaking a solar cell is a particular p-n junction where the diffusion process (diode D1) co-exists with the generation and recombination effect of the charge carrier (diode D2) induced by the presence of crystalline defects. This model was tested using data relevant to the AZUR SPACE $28 \%$ solar cell, as reported in the datasheet provided by the Manufacturer, and available on company web-site.

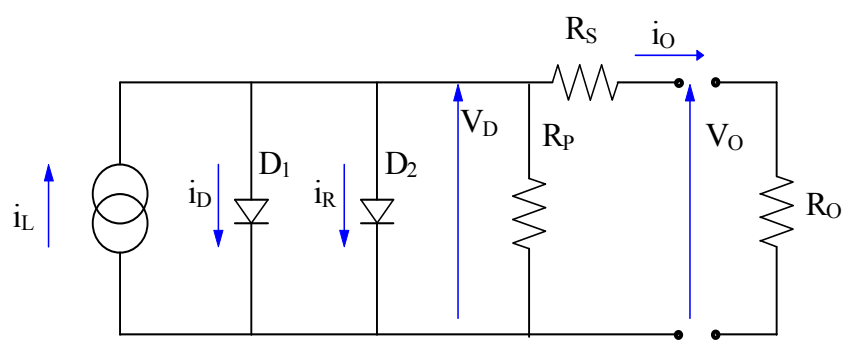

Fig. 4. Equivalent Circuit of solar cell

The relevant Kirchhoff equations are:

$$
i_{o}=i_{L}-i_{D} \cdot\left[\exp \left(\frac{q \cdot V_{D}}{k \cdot T}\right)-1\right]-i_{R} \cdot\left[\exp \left(\frac{q \cdot V_{D}}{2 k \cdot T}\right)-1\right]-\frac{V_{D}}{R_{p}}
$$




$$
V_{o}=V_{D}-R_{S} \cdot i_{o}
$$

Where:

$\mathrm{K}=1.381 \times 10^{-23}\left(\mathrm{~J} /{ }^{\circ} \mathrm{K}\right)$ is the Boltzmann constant;

$\mathrm{q}=1.602 \times 10^{-19}(\mathrm{C})$ is the electron charge;

$i_{L}, i_{D}$ e $i_{R}$ are respectively the current due to illumination, and the reverse currents of the diodes $\mathrm{D}_{1}$ e $\mathrm{D}_{2}$; they are function of the temperature.

The equations (1) give the output voltage $V_{o}$, and current $I_{o}$ as function of the voltage drop $V_{d}$ over the diodes $D_{1}$ and $D_{2}$. The second and third term of $\left(1_{a}\right)$ represent the typical voltage-current laws of the diodes, and the currents $i_{D}$ and $i_{R}$ are the reverse currents of the diodes dependent from the physics of the solar cell.

In general, the solar cell is characterised by the following data provided in the manufacturer's data sheet, the table below gives the values relevant to the one used for testing the model:

$\begin{array}{lll}\mathbf{I}_{\mathbf{s c}} & 506.0 \mathrm{~mA} & \text { Short circuit current; } \\ \mathbf{I}_{\mathbf{m p}} & 487.0 \mathrm{~mA} & \text { Maximum power current; } \\ \mathbf{V}_{\mathbf{m p}} & 2371.0 \mathrm{mV} & \text { Maximum power voltage; } \\ \mathbf{V}_{\mathbf{~ o c}} & 2667.0 \mathrm{mV} & \text { Open circuit voltage; } \\ \mathbf{d I}_{\mathbf{s c}} / \mathbf{d T} & 0.32 \mathrm{~mA} /{ }^{\circ} \mathrm{K} & \text { Short circuit current temperature coefficient } \\ \mathbf{d I}_{\mathbf{m p}} / \mathbf{d T} & 0.28 \mathrm{~mA} /{ }^{\circ} \mathrm{K} & \text { Max. power current temperature coefficient } \\ \mathbf{d V}_{\mathbf{m p}} / \mathbf{d T} & -6.1 \mathrm{mV} /{ }^{\circ} \mathrm{K} & \text { Max. power voltage temperature coefficient; } \\ \mathbf{d V}_{\mathbf{o d}} \mathbf{d T} & -6.0 \mathrm{mV} /{ }^{\circ} \mathrm{K} & \text { Open circuit voltage temperature coefficient. }\end{array}$

Such data are given in AM0 $\left(1367.0 \mathrm{~W} / \mathrm{m}^{2}\right)$ conditions at $\mathrm{T}_{\text {ref }}=28^{\circ} \mathrm{C}\left(301.15^{\circ} \mathrm{K}\right)$ reference temperature.

Usually the series resistance is around $300 \mathrm{~m} \Omega$ for a triple junction cell, while for the shunt one $500 \Omega$ maybe assumed. Such resistances may be considered in a first approximation as constant in the operating temperature range of the cell.

The values of $i_{L}, i_{D}$ and $i_{R}$ at the reference temperature can be calculated with the (1) in the three main point of the V-I curve; short circuit, maximum power and open circuit, by the least square method.

The next step is to define how these currents change with temperature.

Concerning $\mathbf{i}_{\mathbf{D}}$ e $\mathbf{i}_{\mathbf{R}}$ it is possible to write:

$$
\begin{gathered}
i_{D}=C_{D} \cdot T^{5 / 2} \cdot \exp \left(\frac{E_{g}}{n_{1} \cdot T}\right) \\
i_{R}=C_{R} \cdot \exp \left(\frac{E_{g}}{n_{2} \cdot k \cdot T}\right)
\end{gathered}
$$

Where $C_{D}$ and $C_{R}$ are constants independent from temperature, and $E_{g}$ is the Energy of the prohibited band gap:

$$
E_{g}=E_{g 0}-\frac{\left(\alpha_{e} \cdot T^{2}\right)}{\left(T+\beta_{e}\right)} \quad\left(\mathrm{mA} / \mathrm{cm}^{2}\right)
$$


With $\mathrm{E}_{\mathrm{g} 0}=1.41 \mathrm{eV}, \mathrm{a}_{\mathrm{e}}=-6.6 \times 10^{-4} \mathrm{eV} /{ }^{\circ} \mathrm{K}$, and $\beta_{\mathrm{e}}=552^{\circ} \mathrm{K}$.

The current $i_{\mathrm{L}}$ due to illumination is given instead by

$$
i_{L}(T)=K(T) \cdot \eta(T) \cdot J_{t o t} \quad\left(\mathrm{~mA} / \mathrm{cm}^{2}\right)
$$

Where $\mathrm{J}_{\text {tot }}$ is light intensity $\left(\mathrm{W} / \mathrm{m}^{2}\right), \mathrm{\eta}(\mathrm{T})$ is the efficiency of the cell, $\mathrm{K}(\mathrm{T})$ is a coefficient to be determined as function of the temperature.

$\mathrm{n}_{1}$ e $\mathrm{n}_{2}$ are two coefficients depending on the adopted solar cell technology:

At this point all the terms of the equations (1) can be defined at any temperature and by setting as input the operating voltage $V_{o}$ and solving the system by the Newton-Raphson numerical scheme is possible to calculate the output current $i_{\circ}$.

Figure 5 shows the V-I curves relevant to Triple Junction AZUR SPACE solar cell starting from the datasheet available on the web site, as function of temperature at Begin Of Life (BOL); the black asterisks are the maximum power points calculated according to the datasheet. In figure $6 \mathrm{~V}$-I curves for different illumination levels are reported.

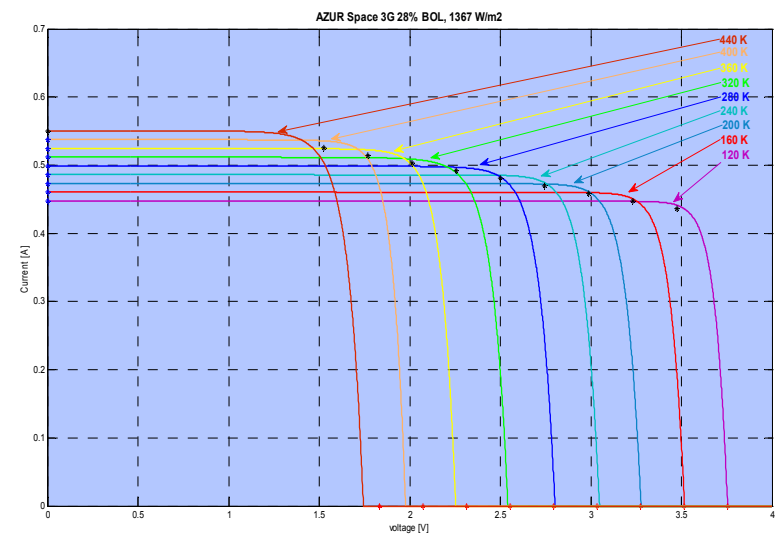

Fig. 5. Computed V-I curves as function of temperature using AZUR SPACE 3G 28\% data

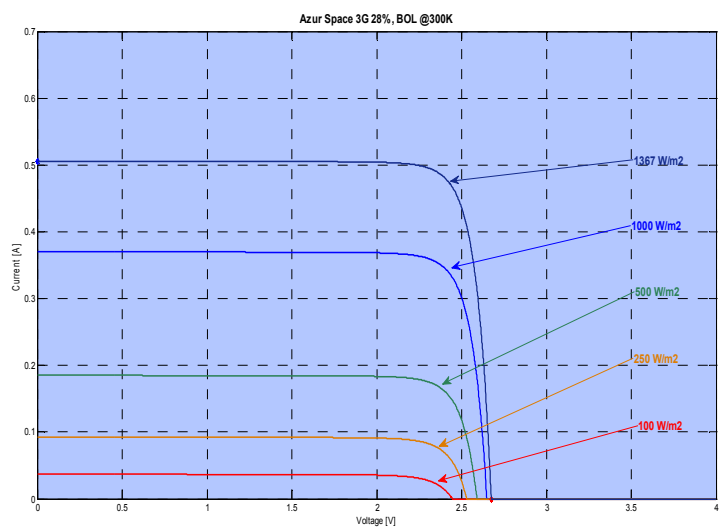

Fig. 6. Computed V-I curves as function of illumination using AZUR SPACE 3G 28\% data 


\section{Solar panel thermal model}

What said above clearly highlights the need of a thermal model of the solar panel taking into consideration the heat exchange on both sides of it in case of a deployable one; or usually considering the rear side as adiabatic in case of the panel is body mounted. The panel is considered as rigid, with honeycomb structure on which the solar cells are applied; the following table reports the components recognizable in solar panel cross-section:

\begin{tabular}{|l|c|}
\hline $\begin{array}{c}\text { Components from } \\
\text { front to rear side }\end{array}$ & $\begin{array}{c}\text { Thickness, } \\
\mu \mathrm{m}\end{array}$ \\
\hline Coverglass & $150-500$ \\
\hline Coverglass adhesive & $50-100$ \\
\hline Solar cell & $100-200$ \\
\hline Cell adhesive & 100 \\
\hline Kapton insulation & 50 \\
\hline Face skin (Carbon fibre) & - \\
\hline Adhesive & 100 \\
\hline Honeycomb (Aluminium) & Up to $4 \mathrm{~cm}$ \\
\hline Adhesive & 100 \\
\hline Face skin (Carbon fibre) & - \\
\hline Black paint & 50 \\
\hline
\end{tabular}

Table 1. Solar panel composition

The panel temperature is computed taking into account the direct sun radiation, the albedo radiation, the irradiation to deep space, and irradiation between the earth surface and the panel itself. The sun illumination is variable during the year and considering only missions around the earth it may range between 1315.0 (summer solstice) and $1426 \mathrm{~W} / \mathrm{m} 2$ (winter solstice), while the albedo of the earth surface is about $30 \%$ of the incident sun illumination. The panel exchanges heat with the deep space and this is seen as a black body at $3^{\circ} \mathrm{K}$, as well as the earth irradiates as a black body at $250^{\circ} \mathrm{K}$. The following simplifying assumptions can been made; a deployed solar panel does not exchange heat with the outer surfaces of the satellite body, a body mounted solar panel is adiabatically isolated from the rest of the satellite body and finally the panel surface temperature is considered as uniform. The conduction across the panel also plays an important role, and it has to be taken into account in case of a deployed solar panel. At a first glance, the in-plane conductivity may be neglected, this because under the hypothesis of uniform temperature over the panel, the heat exchange between adjacent cells is basically zero.

The thermal equilibrium is computed by solving the differential equation which takes into account the different heat exchange modalities.

$$
C \cdot \frac{d T}{d t}=Q_{\text {Rad }}+Q_{\text {Alb }}+Q_{\text {Earth }}+Q_{\text {Space }}+Q_{\text {cond }}
$$

Where:

$$
Q_{\text {Rad }}=\alpha(1-\eta) \cos \vartheta \cdot J
$$


It is the contribution of the direct sun radiation $\mathrm{J}$ that is not converted into electrical power by the photovoltaic cell;

$$
Q_{a l b}=\alpha(1-\eta) \cdot F \cdot A l \cdot F_{1-2} \cdot J
$$

It is the contribution of the albedo radiation;

$$
Q_{\text {Earth }}=\sigma \cdot \varepsilon \cdot F_{12} \cdot\left(T_{E}^{4}-T^{4}\right)
$$

It is the heat exchanged with the Earth surface.

$$
Q_{\text {Space }}=\sigma \cdot \varepsilon \cdot\left(1-F_{12}\right) \cdot T^{4}
$$

It is the heat released to the deep space.

$$
Q_{\text {cond }}=\frac{\left(T_{\text {front }}-T_{\text {rear }}\right)}{\Delta x} \cdot k
$$

Is the heat transmitted by conduction between the front and rear faces of the panel at $T_{\text {front }}$ and $\mathrm{T}_{\text {rear }}$ temperature respectively.

The parameters appearing in these equations have the following meanings:

$\mathrm{C}=$ thermal capacitance of the panel per unit area, main contribution is provided the honeycomb structure;

$\alpha=$ solar cell absorptivity;

$\varepsilon=$ solar cell emissivity;

$\mathrm{Al}=$ albedo coefficient, about 0.3 for earth;

$\mathrm{F}=$ albedo visibility factor;

$\mathrm{F}_{12}=$ View factor between radiating surface and planet

$\sigma=$ Stephan-Boltzmann, constant: $5.672 \times 10^{-8} \mathrm{~W} /\left(\mathrm{m}^{2} \times{ }^{\circ} \mathrm{K}^{4}\right)$;

$\mathrm{T}_{\mathrm{E}}=$ Black body equivalent temperature of the earth;

$\vartheta$ = incidence angle of the sunlight on the panel;

$\mathrm{k}=$ panel transverse thermal conductivity;

$\Delta \mathrm{x}=$ panel thickness;

The radiating view factor of a flat surface with respect to the Earth surface is function of the altitude $h$, earth radium $R \oplus$ and the angle $\lambda$ between the nadir and the normal to the panel. The albedo view factor is computed according to the following formulas:

$$
F_{a l b}=\left[1-\cos \left(\beta_{\text {app }}\right)\right] \cdot \cos (\beta)
$$

Where $\beta$ is the angle between the nadir and the earth-sun direction:

$$
\beta_{\text {app }}=\arcsin \left(\frac{R_{\oplus}}{h+R_{\oplus}}\right)
$$

The integration in the time domain of the equation (5) gives the actual temperature of the panel along the propagation of the orbit in eclipse and sunlight, taking into account the orientation of the panel itself with respect to the earth and the sun. The thermal model 
exposed so far is sufficient for the design of a solar array for space application at system level.

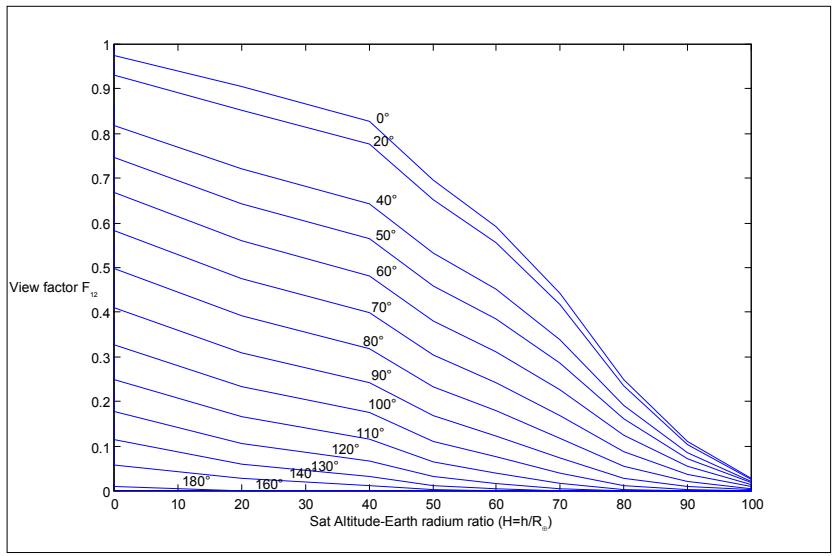

Fig. 7. View Factors $\mathrm{F}_{12}$ as function of $\mathrm{H}=\mathrm{h} / \mathrm{R}_{\oplus}$, parameter: $\lambda$

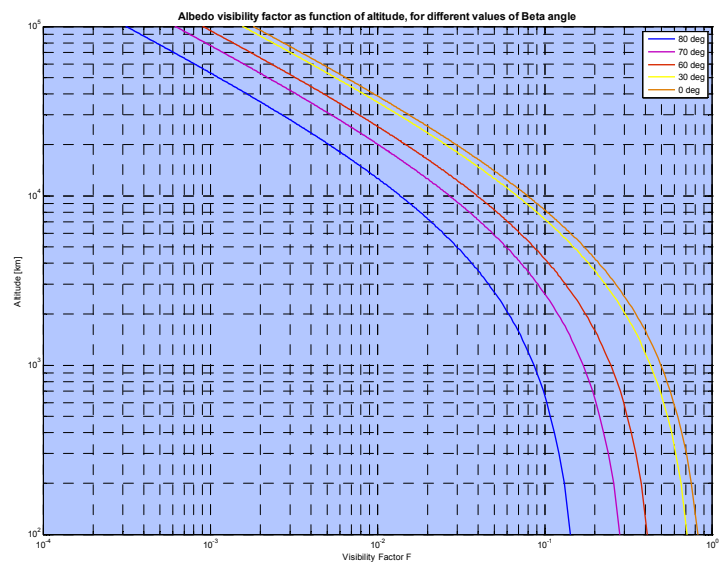

Fig. 8. Albedo Visibility factor $F$ as function of $h$ for different $\beta$ value

\section{Degradation due to space environment}

Space is a hostile environment for the electronic components in general and solar cells in particular. The sun radiates energy in almost the whole electromagnetic spectrum, from radio waves to gamma rays, and abundant charged particles impinging on a surface cause damages which cumulate over the mission lifetime (fluence $\Phi$ ). The behaviour of solar cells in a radiation environment can be described in terms of the changes in the engineering output parameters of the devices. The radiation usually of interest in the study of degradation of materials and devices consists of energetic or fast massive particles (i.e. electrons, protons, neutrons or ions). The major types of radiation damage phenomena in 
solids which are of interest to the solar array designer are ionisation and atomic displacement.

Ionisation occurs when orbital electrons are removed from an atom or molecule in gases, liquids, or solids. The measure of the intensity of ionising radiation is the roentgen. The measure of the absorbed dose in any material of interest is usually defined in terms of absorbed energy per unit mass. The accepted unit of absorbed dose is the $\mathrm{rad}(100 \mathrm{erg} / \mathrm{g}$ or $0.01 \mathrm{~J} / \mathrm{kg}$ ). For electrons, the absorbed dose may be computed from the incident fluence $\Phi$ (in $\mathrm{cm}^{-2}$ ) as: Dose $(\mathrm{rad})=1.6 \times 10^{-8} d E / d x \Phi$, where $d E / d x\left(\right.$ in $\mathrm{MeV} \mathrm{cm}^{2} \mathrm{~g}^{-1}$ ) is the electron stopping power in the material of interest. In this manner, the effects of an exposure to fluxes of trapped electrons of various energies in space can be reduced to an absorbed dose. By the concept of absorbed dose, various radiation exposures can be reduced to absorbed dose units which reflect the degree of ionisation damage in the material of interest. This concept can be applied to electron, gamma, and X-ray radiation of all energies. Several ionisation related effects may degrade the solar cell assemblies. The reduction of transmittance in solar cell cover glasses is an important effect of ionising radiation.

The basis for solar cells damage is the displacement of semiconductor atoms from their lattice sites by fast particles in the crystalline absorber. The displaced atoms and their associated vacancies after various processes form stable defects producing changes in the equilibrium of carrier concentrations and in the minority carrier lifetime. Such displacements require a certain minimum energy similar to that of other atomic movements. Seitz and Koehler [1956] estimated the displacement energy is roughly four times the sublimation energy. Electron threshold energies up to $145 \mathrm{keV}$ have been reported. Particles below this threshold energy cannot produce displacement damage, therefore the space environment energy spectra are cut off below this value. The basic solar cell equations (1) may be used to describe the changes which occur during irradiation. This method would require data regarding the changes in the light generated current, series resistance, shunt resistance, but most investigations have not reported enough data to determine the variations in the above parameters. The usual practice is then to reduce the experimental data in terms of changes in the cell short circuit current $\left(I_{\mathrm{sc}}\right)$, open circuit voltage $\left(V_{\mathrm{oc}}\right)$, and maximum power $\left(P_{\max }\right)$. The variation of common solar cell output parameters during irradiation can be described as shown for $I_{\mathrm{sc}}$ in the following case:

$$
I_{\mathrm{sc}}=I_{\mathrm{sc} 0}-C \log \left(1+\Phi / \Phi_{\mathrm{x}}\right)
$$

Where $\Phi_{\mathrm{x}}$ represents the radiation fluence at which $I_{\mathrm{sc}}$ starts to change to a linear function of the logarithm of the fluence. The constant $C$ represents the decrease in $I_{\mathrm{sc}}$ per decade in radiation fluence in the logarithmic region. In a similar way, for the $\mathrm{V}_{\mathrm{oc}}$ it can be written;

$$
V_{\mathrm{oc}}=V_{\mathrm{oc} 0}-C^{\prime} \log \left(1+\Phi / \Phi_{\mathrm{x}}\right) .
$$

And for the maximum power;

$$
P_{\max }=P_{\max 0}-C^{\prime \prime} \log \left(1+\Phi / \Phi_{\mathrm{x}}\right) .
$$

In the space environment a wide range of electron and proton energies is present; therefore some method for describing the effects of various types of radiation is needed in order to get a radiation environment which can be reproduced in laboratory. It is possible to determine an equivalent damage due to irradiation based upon the changes in solar cell parameters which are in some way related to the minority carrier diffusion length. 
The $I_{\mathrm{sc}}$ variation in each environment is described by the equation for $I_{\mathrm{sc}}$. In this case, two constants, $C$ and $\Phi_{\mathrm{x}}$, are required to describe the changes in $I_{\mathrm{sc}}$. It has been shown that the constant $C$, under solar illumination, does not greatly vary for different radiation environments. For electron irradiations in the $1 \mathrm{MeV}$ and greater range, $C$ is about 4.5 to 5.5 $\mathrm{mA} \mathrm{cm}-2 /$ decade. In case of proton and neutron, $C$ approaches 6 to $7 \mathrm{~mA} \mathrm{~cm}^{-2} /$ decade.

For solar cells with the same initial $I_{\mathrm{sc}}$, the constant $\Phi_{\mathrm{x}}$ is a measure of the damage effectiveness of different radiation environments. The constant $\Phi_{\mathrm{x}}$ for a particular radiation can be determined graphically on a semi-log plot at the intersection of the starting $I_{\mathrm{sc}}$ and the extrapolation of the linear degradation region.

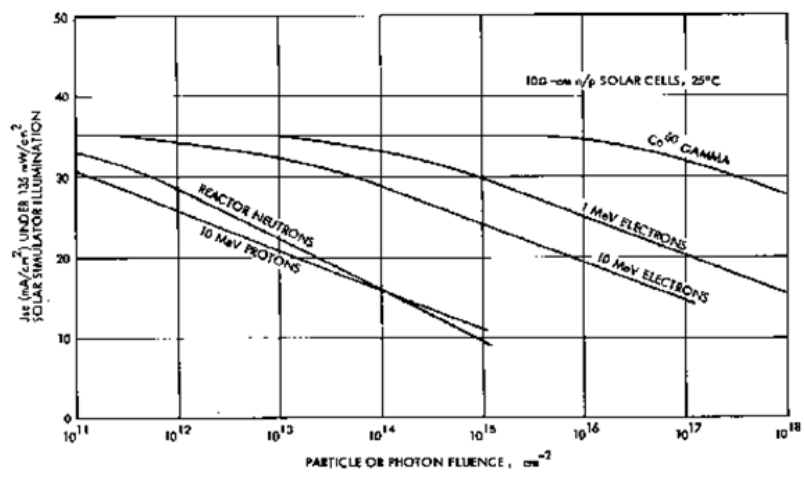

Fig. 9. Variation of solar cell short circuit current with fluence for various radiations

It is the practice to define an arbitrary constant referred to as the critical fluence $\Phi_{c}$. One method of defining this value is that fluence which degrades a solar cell parameter $25 \%$ below its BOL state. But such a parameter is valid only when comparing cells with similar initial parameters. To eliminate this problem, critical fluence may be alternatively defined as that fluence which will degrade a cell parameter to a certain value. By use of the critical fluence or the diffusion length damage coefficient, it is possible to construct a model in which the various components of a combined radiation environment can be described in terms of a damage equivalent fluence of a selected mono-energetic particle. $1 \mathrm{MeV}$ Electrons are a common and significant component of space radiation and can be produced conveniently in a test environment. For this reason, $1 \mathrm{MeV}$ electron fluence has been used as a basis of the damage equivalent fluences which describe solar cell degradation.

The degradation due to radiation effects on solar cell cover-glass material in space is difficult to assess. The different radiation components of the environment act both individually and synergistically on the elements of the shielding material and also cause changes in the interaction of shielding elements. However, the most significant radiation effects in cover materials involve changes in the transmission of light in the visible and near infrared region.

The methods for estimating solar cell degradation in space are based on the techniques described by Brown et al. [1963] and Tada [1973ab]. In summary, the omni-directional space radiation is converted to a damage equivalent unidirectional fluence at a normalised energy and in terms of a specific radiation particle. This equivalent fluence will produce the same damage as that produced by omni directional space radiation considered if the relative damage coefficient (RDC) is properly defined to allow the conversion. When the equivalent 
fluence is determined for a given space environment, the parameter degradation can be evaluated in the laboratory by irradiating the solar cell with the calculated fluence level of unidirectional normally incident flux. The equivalent fluence is normally expressed in terms of $1 \mathrm{MeV}$ electrons or $10 \mathrm{MeV}$ protons. The three basic input elements necessary to perform degradation calculations are:

1. degradation data for solar cells under normal incidence $1 \mathrm{MeV}$ electron irradiation;

2. effective relative damage coefficients for omni-directional space electrons and protons of various energies for solar cells with various cover-glass thicknesses;

3. Space radiation environment data for the orbit of interest.

The equivalent $10 \mathrm{MeV}$ proton fluence can be converted to equivalent $1 \mathrm{MeV}$ electron fluence as follows: $\Phi_{1 \mathrm{MeV} \mathrm{e}}=3000 \Phi i_{10 \mathrm{MeV}}$.

In cases when the cell degradation is entirely dominated by proton damage, the cell degradation could be estimated more accurately by calculating the equivalent $10 \mathrm{MeV}$ proton fluence and using $10 \mathrm{MeV}$ proton cell damage data, than by using the equivalent 1 $\mathrm{MeV}$ electron fluence and electron data.

To use cover-glass darkening data, a procedure is necessary to evaluate the absorbed dose produced by the various radiation components of the space environment. The procedure is similar to that used for equivalent fluence, with the exception that the absorbed dose varies with depth in the cover material.

\section{The power and energy budget}

The starting point for the solar array sizing is the correct identification of the power demand throughout the whole mission of the spacecraft.

Such power demand may change during the satellite lifetime either because of different operational modes foreseen during the mission or, more simply, because of degradation of the electrical performances of the electrical loads (in majority electronic units).

Taking into consideration what just said, an analysis of power demand is performed, including peak power, of all the loads installed either in the platform or as payload for each identified phase of the mission. Because of presence of sun eclipses, and possible depointings along the orbit, an analysis of the energy demand is also performed, this because in case of insufficient illumination the on board battery will supply the electrical power, and the solar array has to be sized in order to provide also the necessary power for its recharge. The power budget is based on peak power demands of the loads, while the energy budget is based on average consumptions.

It is good practice consider power margins both at unit and electrical system level.

The consumption of each unit is calculated considering the following criteria:

- $20 \%$ margin with respect to expected power demand if the unit design is new.

- $10 \%$ margin if the unit design has a heritage from a previous similar one.

- $5 \%$ margin if the unit is recurrent.

Several electronic units work in cold or hot redundancy; this has to be taken into account when summing the power demands.

Once the power demand is defined including the margins above, it is advisable to add $20 \%$ extra margin at system level and defined at the beginning of the project. Such margin is particularly useful during the satellite development in order to manage eventual power excesses of some units beyond the margins defined at unit level. In this way eventual Request For Deviation (RFD) issued by the subcontractors can be successfully processed 
without endangering the whole spacecraft design. This is particularly true for scientific missions, where many times the development of the instruments may reveal so challenging that an excess of power demand cannot be excluded a priori.

At this point harness distribution losses are introduced, $2 \%$ of the power demand defined with all margins at unit and system level may be a good compromise between losses containment and harness mass.

The Power Control and Distribution Unit (PCDU) is the electronic unit devoted for the solar array and battery power conditioning and regulation, power distribution and protection, execution of received telecommands (i.e. switch on/off of the loads) and telemetry generation. Its power consumption without considering the efficiencies of primary bus power converters depends on the management of the digital interfaces with the on-board computers, the control loop and protection electronics, the value of such consumption is not immediate to calculate but it can be said that a PCDU capable to manage $1 \mathrm{~kW}$ can consume about $30 \mathrm{~W}$. However it consumption strongly depend on the number of implemented distribution lines, and relevant electronic protections.

Now its time to add the power needed for the recharge of the battery, this power strongly depend on the mission profile, and many times the maximum discharge of the battery occurs at launch, from lift-off up to the successful sun acquisition by the satellite with optimal sun pointing of the solar panels. Some times due to the complexity of the satellite design and mission profile it is not possible to have a full recharge of the battery in one orbit before the next eclipse, then the power allocated for such incumbency has to assure a positive battery recharge trend throughout a limited number of orbits.

The power delivered by the solar array is conditioned by suitable power converters in order to provide it to the loads with a regulated voltage, or at list with the voltage varying between a maximum and minimum value. These converters may have an efficiency between 98.5\% and 95\% and the choice of their topology is made according to several criteria and constraint dictated by the overall satellite system design. Such efficiencies are taken into account adding up to an additional $5 \%$ to the budget defined so far.

The harness losses between solar array and PCDU may be calculated having as objective $1 \mathrm{~V}$ voltage drop at the maximum required power; again, considerations about the harness mass can provoke the change of such objective.

Finally, in case of the European ECSS standard (ECSS-E-ST-20C) is considered as applicable, an additional $5 \%$ margin on power availability shall be assured at the satellite acceptance review End of Life (EOL) conditions and one solar array string failed.

\section{Solar array sizing; impact of the power conditioning and electromagnetic constraints}

The definition of the solar array, conceived as a set of solar cells connected in series to form a string and strings connected in parallel cannot be made without considering the power conditioning device placed at its output in order to have the electrical power delivered within a certain voltage range. This is not the suitable seat for a complete examination of all the possible power conditioning and power architecture solutions, what can be said is that there are two main concepts: the Direct Energy Transfer (DET) and the Maximum Peak Power Tracking (MPPT). These two methods of regulation have an important impact on the solar array design not only from the sizing point of view, but also from the electromagnetic compatibility (EMC) one. The following section will detail the impact of the adopted power 
conditioning concept, and some sizing constraints mainly raised by the space environment such as electrostatic discharges and earth magnetic field.

\subsection{Regulation based on Sequential Switching Shunt Regulator $\left(S^{3} R\right)$}

The first concept is based on the use of a shunt regulator; the figure below shows the electric schematic of a cell of a Sequential Switching Shunt Regulator (S3R), several solar array strings can be connected in parallel to the input of the regulator's cell; the voltage at the terminals of the output capacitor (Main Bus capacitor) is regulated by the switching of the MOSFET contained in the blue oval.

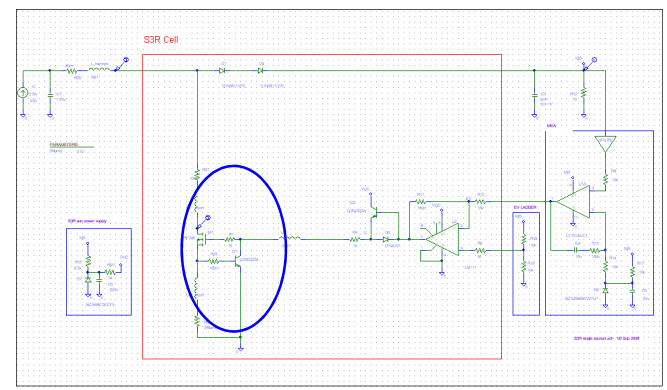

Fig. 10. Electrical Section of a Sequential Switching Shunt Regulator (S3R)

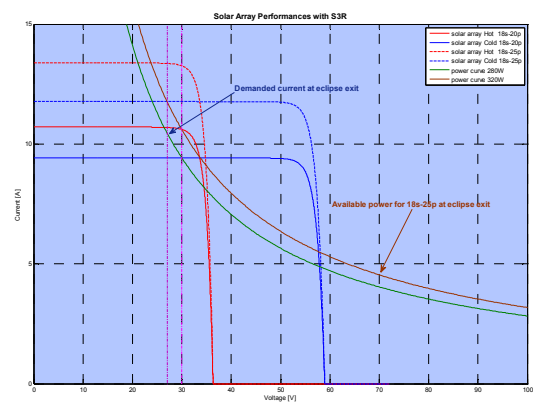

Fig. 11. Solar array working points as function of required power

The operating voltage of the solar array is constant and equal to main bus nominal voltage plus the voltage drops due the two diodes in series along the line, the solar array harness, and the blocking diode placed at the string positive output. In case of a fully regulated power bus, this operating voltage remains fixed during both sunlight and eclipse periods throughout the orbit; if the power bus is instead a battery regulated one it implies that the bus voltage decreases during eclipse periods, when the battery discharges, provoking a migration of the operating point of the solar array towards the short circuit one.

Supposing a power need of $280 \mathrm{~W}$, Figure 11 shows that a solar array composed of 20 strings of 18 cells $(18 \mathrm{~s}-20 \mathrm{p})$, at the eclipse exit $\left(\mathrm{V}_{\text {array }}=27 \mathrm{~V}\right)$ cannot provide the required power. In this condition the battery keeps discharging, lowering further down the operating voltage. This power bus lock-up has to be avoided increasing the number of strings in parallel. Adding 5 more strings (i.e. $25 \%$ more) the solar array can deliver $320 \mathrm{~W}$ at $27 \mathrm{~V}$ when cold; 
therefore $40 \mathrm{~W}$ become available to assure the battery charge. However, this increase might not be enough for assuring a full recharge of the battery in one orbit, or a positive recharge trend through several orbits; and an assessment of the energy budget by numerical simulation becomes necessary, taking into account orbital and attitude constraints.

\subsection{Regulation based on Maximum Peak Power Point Tracker (MPPT)}

The MPPT concept is based on the use of a switching dc-dc converter; usually it has a buck topology, where the primary voltage at solar array side is always higher of the secondary one on the distribution bus. Figure 12 shows an example of this type of converter. There are three control loops; a conductance control of the output current, an output voltage controller, and the Maximum Peak Power Tracker which regulates the output voltage of the solar array around the maximum power point in case of maximum power demand. In all the cases the required power is lower than the maximum available one the operating voltage of the solar array is kept between the maximum power voltage and the open circuit one.

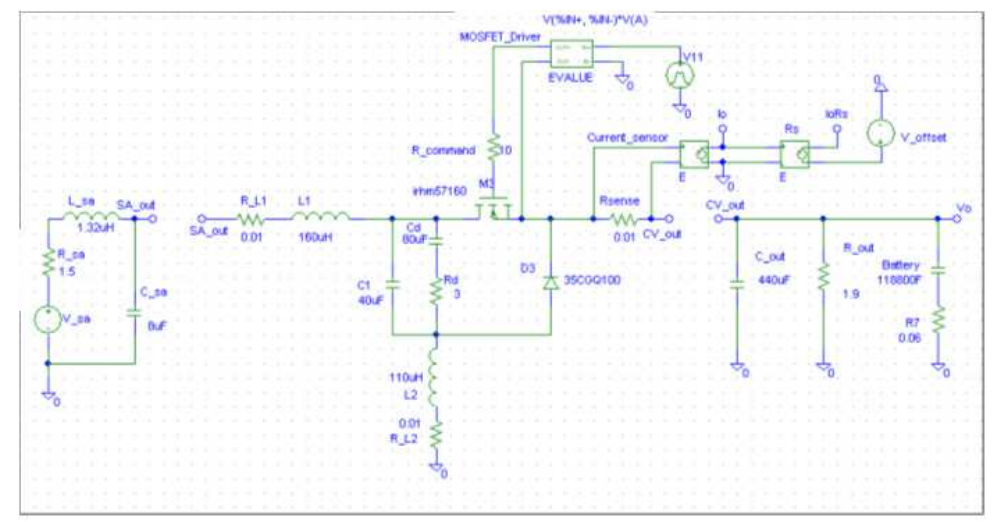

Fig. 12. Low ripple Buck converter topology

When this power conditioning concept is applied the solar array operating voltage is always independent from the bus one. Hence the phenomenon of the lock-up mentioned for the S3R is not present and the solar array does not need to be sized in order to cope with such issue.

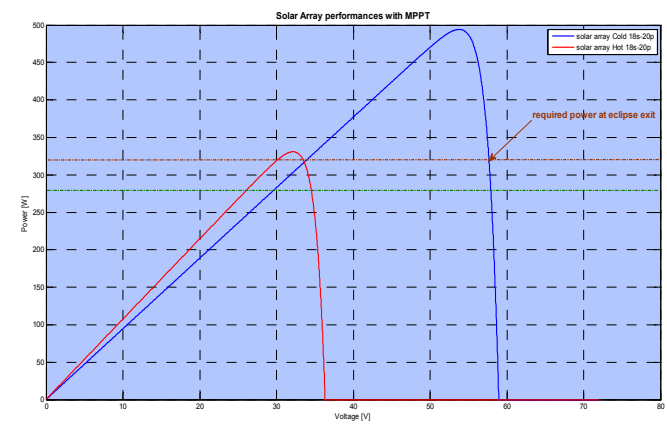

Fig. 13. Solar array P-V curves and required power, MPPT power conditioning 
Figure 13 clearly shows that the original array composed of 20 strings is now capable to deliver the needed power in both hot and cold conditions, providing power to the loads $(280 \mathrm{~W})$ and the additional $40 \mathrm{~W}$ for the recharge of the battery.

Clearly from the sizing point of view of the array, the MPPT provides unquestionable benefits, but the price to be paid consist in additional mass (inductances and capacitances, as it can be seen in figure 12), and higher complexity because of the presence of three control loops.

\subsection{Electromagnetic Compatibility (EMC)}

The design of a spacecraft solar array and its power conditioner has to satisfy several requirements, not only in terms of mass, dimensions and power output, but also in terms of electromagnetic compatibility. This is particularly true for scientific mission, when instruments highly sensitive to electromagnetic fields may be boarded. In these cases it becomes crucial for the success of the mission to know which electromagnetic fields are generated at solar array level due to the circulating current and its frequency content, once this is connected to the power conditioning unit. The wires connecting the solar array to the PCDU, via the Solar Array Driving Mechanism (SADM) when necessary, are always twisted pairs (positive and return), but the return connections of the strings are routed on the rear side of the panel, they are not twisted of course, hence the solar array can behave as a transmitting antenna at frequencies which may result incompatible with some of the equipments on board.

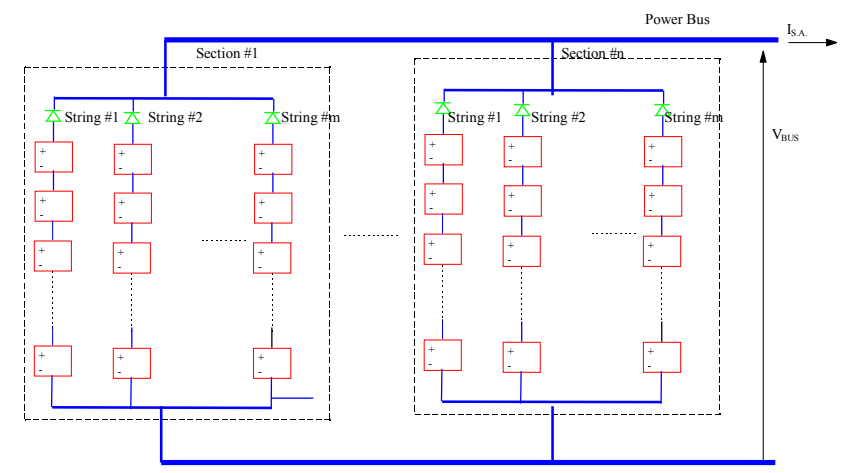

Fig. 14. Solar array electrical scheme

These issues are strongly dependent on the power conditioning approach adopted.

In the case of the S3R, with reference to figure 10, it can be seen that within the blue oval there is the shunt switch (MOSFET) together with a linear regulator in order to limit the current spikes at the regulator input when the MOSFET switches ON/OFF. Such spikes are strongly dependent on the total output capacitance of the strings connected in parallel and hence from the capacitance of the single triple junction solar cell. Fewer cells are in a string, or more strings in parallel, higher is this capacitance. The linear regulator can reduce the amplitude of the spikes by a suitable sizing of the dump resistor. For sake of completeness, the inductances present in the circuit diagram are the parasitic ones. Figure 15 shows the frequency spectrum of the current circulating in the harness between solar array and power regulator for different values of the dump resistor. The next figure 16 instead shows the 
frequency spectrum of the current for the same solar array section when the power conditioning is made by a buck converter with a MPPT control loop. It can be immediately seen that in case of MPPT power conditioning the current ripple on the solar array harness is much lower at low frequencies, not higher than $8 \mathrm{~mA}$; and therefore such solution may be interesting when the power subsystem has to cope to very stringent requirements from EMC point of view.

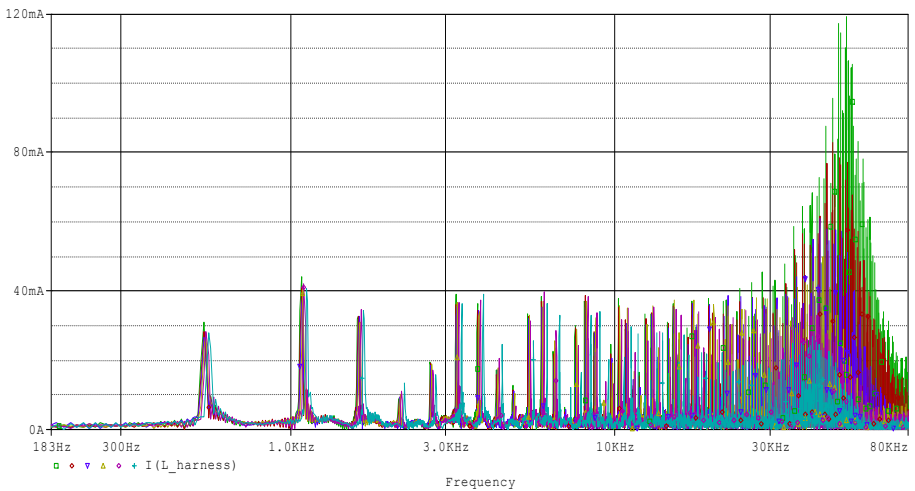

Fig. 15. Frequency spectrum of Solar Array output current for $\mathrm{S}^{3} \mathrm{R}$ power conditioning

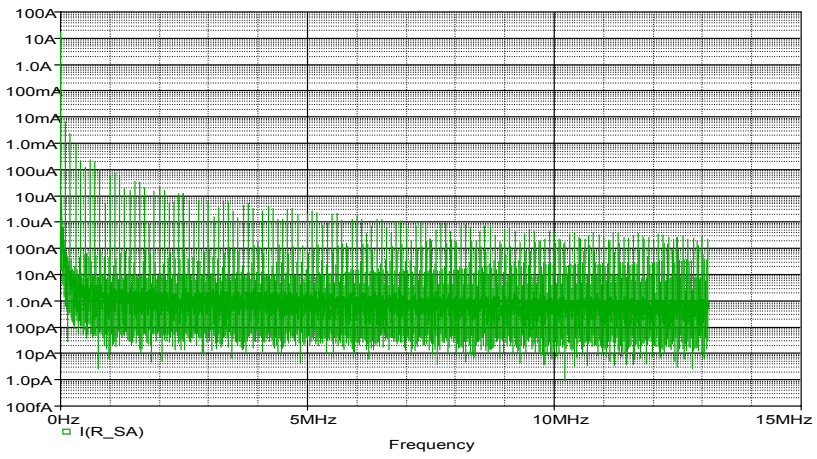

Fig. 16. Frequency Spectrum of Solar Array output current for MPPT power conditioning

\subsection{Effect of the Earth magnetic field}

The interaction between the Earth magnetic field $\boldsymbol{B}$ and the currents circulating in each string generate a torque disturbing the desired attitude of the whole spacecraft. The magnetic moment $\boldsymbol{M}$ due to the current is given by

$$
M=I \cdot A
$$

Where $I$ is the current and $A$ is the area of the current loop; in the case of the solar array this area corresponds in a first approximation to cross section of the panel substrate; on the front face of it the cells are mounted, on the rear face the return harness is implemented.

The resulting torque is 


$$
T=M \times B=M \cdot B \cdot \sin \vartheta
$$

The direction of the torque is such that the dipole tends to orient itself parallel to lines of force of $\boldsymbol{B}$, minimizing the potential energy and achieving a stable position.

This torque has to be in principle neutralised by the Attitude and Orbit Control System of the satellite, which implies the usage of thrusters (i.e. fuel consumption) or increased authority of magneto-torques and/or reaction wheels (electrical power and mass impact).

Clearly there are two ways for the minimisation of this torque; the first one is the minimisation of the areas of the current loops; the second one concern the layout of the solar array strings; adjacent strings can be disposed on the panels in opposite directions, such that the individual torques generated are balanced. With this solution, solar cells having the positive terminal at the string open circuit voltage will lay very close to cells having the negative terminal at $0 \mathrm{~V}$. And this opens the door to another issue to be faced.

\subsection{Electrostatic Discharges (ESD)}

The space plasma is the cause of the accumulation of electrostatic charges on the spacecraft surfaces. The energy of the plasma changes with the altitude; it is around 10,000 eV at about $36,000 \mathrm{~km}$ (Geostationary Orbits, GEO) decreasing to $0.1 \mathrm{eV}$ for below 1,000 km (Low Earth Orbits, LEO), within the Van Allen Belts. For what concern the solar arrays it can be said that the interconnections between solar cells and the cell edges are exposed to plasma, and the output voltage resulting at the terminals of a string plays an important role. The worst scenario occurs at $\mathrm{BOL}$, at the minimum operative temperature (eclipse exit). In these conditions the open circuit voltage is at the maximum value, if triple junction solar cells are used and a string is for instance composed of 34 cells, this voltage can be above $90 \mathrm{~V}$; this is the maximum voltage between two adjacent cells.

The value of the maximum current that can flow through a conductive part of the array (usually the current of a single string if each is protected by a diode) is also important; indeed it has been proofed that in order to have a self sustained secondary arc, minimum value of the current for a particular voltage is needed. In case of ECSS standard applies, in particular "Spacecraft Charging - Environment Induced Effects on the Electrostatic Behaviour of Space Systems (ECSS-E-20-06)", then it can be said that no tests are required to prove the safety of the solar array to secondary arcing when the maximum voltage-current couple available between two adjacent cells on the panel, separated with $0.9 \mathrm{~mm}$ as nominal value, is below the threshold in the following table:

\begin{tabular}{|l|l|l|}
\hline VOLTAGE & CURRENT & COMMENTS \\
\hline $70 \mathrm{~V}$ & $0.6 \mathrm{~A}$ & No self sustained secondary arcing possible \\
\hline $50 \mathrm{~V}$ & $1.5 \mathrm{~A}$ & No self sustained secondary arcing possible \\
\hline $30 \mathrm{~V}$ & $2 \mathrm{~A}$ & No self sustained secondary arcing possible \\
\hline $10 \mathrm{~V}$ & - & Voltage is too low to allow any arcing \\
\hline
\end{tabular}

Table 2. ESD limit conditions

An inter-cell gap between strings of adjacent sections may be defined at $2 \mathrm{~mm}$, cell to cell, that means $1.85 \mathrm{~mm}$ between cover-glasses. Finally, taking into account tolerances of the tools used during manufacturing of the solar array, it results that the distance between adjacent strings is always higher than $1.6 \mathrm{~mm}$ 


\section{Solar array configurations}

The solar arrays mounted on a satellite can have very different shapes, accommodations and dimensions. The configuration of a solar panel is the result of several design iterations made at satellite level, considering the mission requirements, the needed power, the dimensions, mass, and the spacecraft attitude to be kept during the whole lifetime and in all the possible satellite working modes. However three or four main configurations of the solar array can be identified.

\subsection{Spinning satellite}

The first configuration is the one characterising a spinning satellite. The satellite usually has cylindrical shape with the symmetry axis as the rotation one. This configuration was the first one to be adopted; the available power is not elevated with respect to the panel surface, indeed the equivalent active area results from the division of the actual area of panel by $\Pi$. The satellite Meteosat is a good example; this configuration is nowadays rarely used, but in some cases is still interesting for scientific satellites like those of the Cluster mission.

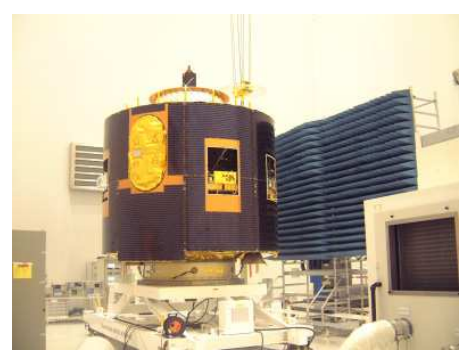

Fig. 17. Solar Array for spinning Satellite, Meteosat Second Generation (Credits: ESA - MSG Team)

\subsection{Body mounted panels}

The second configuration foresees the panels body mounted to the spacecraft walls. The panels are rigidly fixed to the structure and their orientation towards to the sun is never optimal.

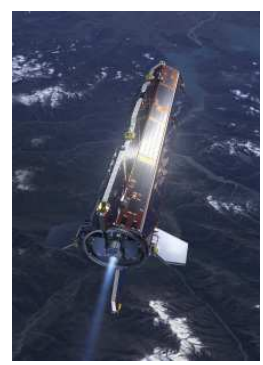

Fig. 18. Body mounted solar array, GOCE (Credits: ESA - AOES Medialab)

This solution has been recently adopted for earth observation and scientific satellites with a reduced power need, no more than $1 \mathrm{~kW}$. In case of earth observation satellites the nadir- 
pointing attitude of the instruments results in highly variable illumination of the panel, therefore the computation energy budget can be quite challenging because the power subsystem may have power coming from both solar array and battery pack at the same time along the orbit. This behaviour may significantly reduce the useful time for the recharge of the battery in sunlight, and an oversized solar panel may be needed. The ESA spacecraft GOCE is a good example of such body mounted panels; two of them are installed on the fixed "wings" of the satellite, the other two are on the "fuselage". It is worth to note that the temperatures on the solar panels are very different between one another, this because of the different illumination levels and different thermal exchange of the wings (remaining colder) with respect to the fuselage (hotter panels). Such configuration, dictated by many other requirements at satellite level, can have a huge impact in the complexity of the power conditioning concept to be adopted.

\subsection{Deployable wings}

The third one is the classical double deployable wing. This solution is classical for telecommunication geostationary satellites. Each wing is moved by a Solar Array Driving Mechanism having the rotation axis perpendicular to the orbital plane. The illumination is optimized by the automatic orientation of the panels. This kind of configuration is the best solution when several kilowatts are needed, as in the case of recent telecom satellites. Each wing is then composed of several panels kept folded at launch, and then progressively deployed by suitable mechanisms at early phase of the mission. The satellite Hylas- 1 gives a good example for such solution.

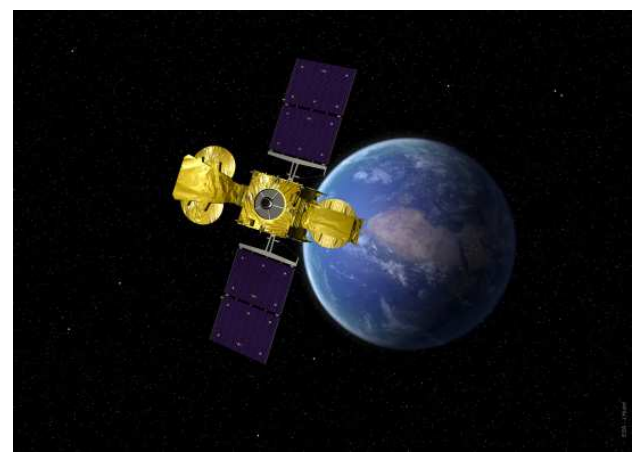

Fig. 19. Deployable Solar panels, Hylas-1 (Credits: ESA - J. Huart.)

\section{Design and simulation examples}

The following two examples will show how a spacecraft solar array, composed of one or more panels having different orientations, provide the needed power during the mission. The examples reported consider body mounted panels, having a fixed orientation with respect to the satellite body axes. This kind of panels is typically used for small and medium satellites, with a power demand less than $1 \mathrm{~kW}$. If on one hand they are relatively cheap and easy to realise, on the other they may require additional efforts for the proper assessment of the energy budget throughout the orbits. This is particularly true in case of the power bus is an unregulated one, having wide voltage variations because of the battery 
charge and discharge cycling. In conclusion their design may be particularly challenging because of their typical small size, many times conditioned by the allowed dimensions and mass of the satellite, and the irregular illumination along the orbit.

The first example concerns an Earth observation satellite made as a cube. Three lateral sides are covered by solar cells; the fourth one accommodates the instruments and is Nadir pointing. The last two sides of the cube are parallel to the orbital plane. This configuration of the satellite is such that the illumination of each panel results to be almost sinusoidal, when the sun-light is incident on the panel itself. The temperatures will follow the same type of law, and the available electrical power as well. The orbit is sun-synchronous, and the transmitters are working when the ground stations are visible. The satellite is small; its required power is about $160 \mathrm{~W}$, and $60 \mathrm{~W}$ are consumed by two different transmitters at different transmission frequencies. Each panel accommodates 8 strings of 18 cells each; the power conditioning is based on the S3R regulator with a battery power bus (battery directly connected to the distribution bus. This architecture is the one which can be prone to the lock-up of the power bus previously described, due to over-discharge of the battery after eclipse periods. The problem is however mitigated by the possibility to have a sun-bathing mode when the satellite passes over the oceans and in any case in the southern hemisphere. In this operative mode two of the three panels will have the common edge oriented towards the Sun, the sunlight incidence will be $45 \mathrm{deg}$. Figure 20 shows when these sun-bathing phases can occur (red ground-track).

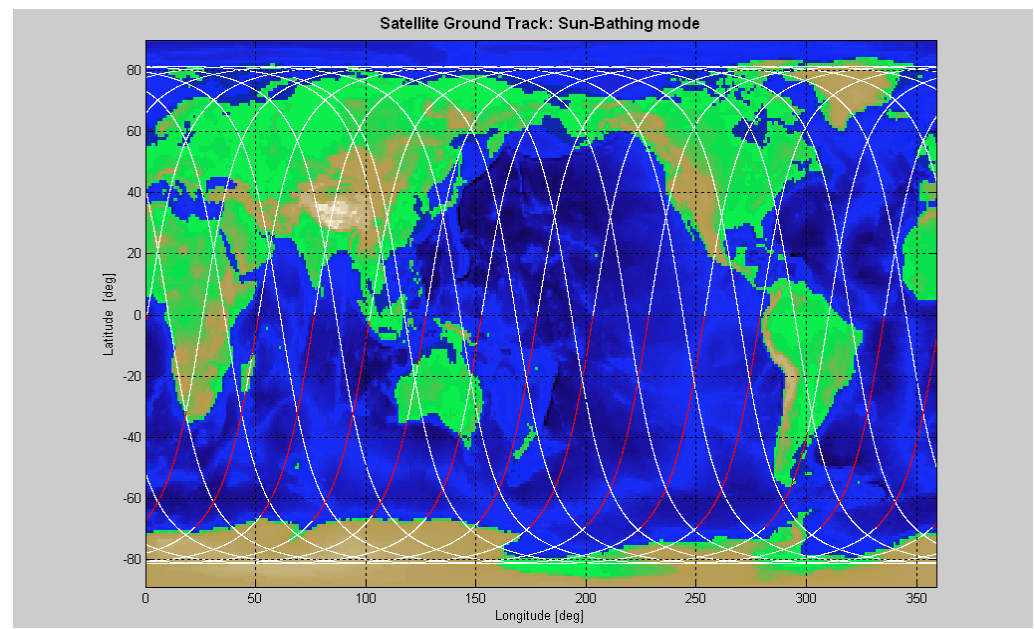

Fig. 20. Satellite ground track

As said, the required power is mainly function of the duty cycle of the transmitters when the ground stations are visible. In this example the three ground stations, typically used for earth observation missions are Kiruna (light blue), Fairbanks (magenta), and Redu (yellow). Figure 21 shows when these stations are visible, together with the eclipse periods (blue ground track). The illuminations of the panels for 24 hours (14 orbits) simulation are reported in figure 22. It can be clearly seen when the sun bathing occurs: panel \#3 shows a constant illumination of about $950 \mathrm{~W}$, while the panel \#2 (magenta) has a slight increase due to the albedo effect; the panel \#1 results to be not illuminated. 


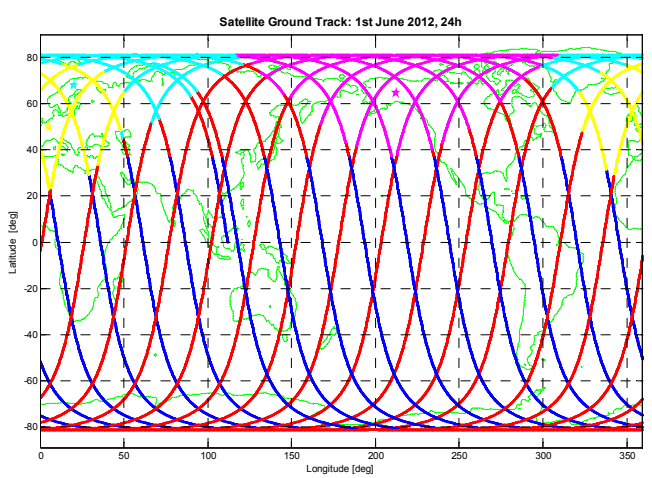

Fig. 21. Ground station visibility and eclipses

Figure 23 shows the calculated temperatures for the three panels. Finally, figure 24 reports the available power from the array, the power exchanged by the battery, and the power required by the loads; from this plot it can be clearly seen the power delivered by the battery is adequately balanced by the power used for recharging them.

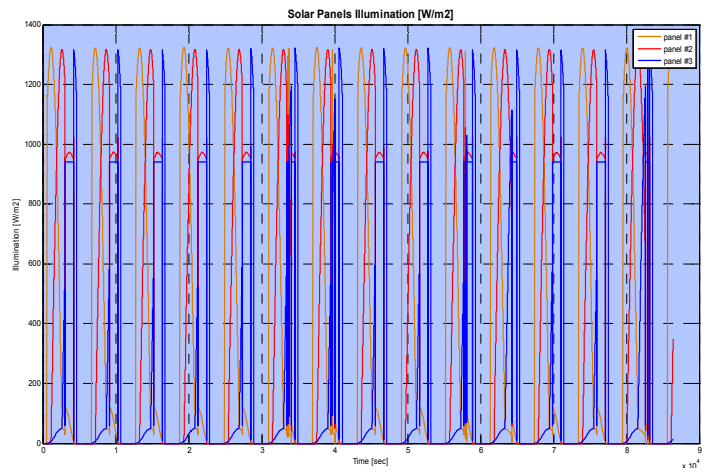

Fig. 22. Illumination of solar panels over 24 hours period

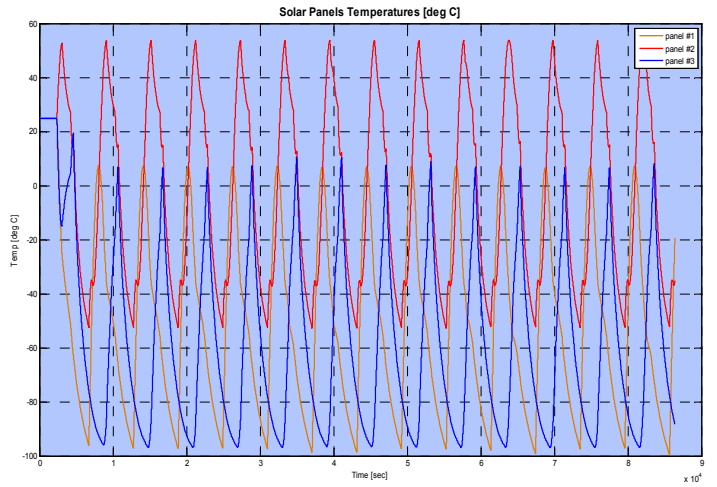

Fig. 23. Temperature of solar panels over 24 hours period 


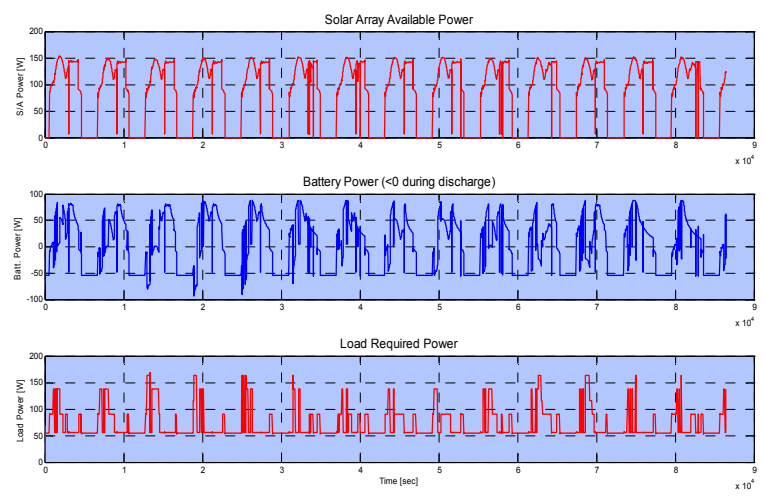

Fig. 24. Power Balance

The second example concern the design of a body mounted solar array which output power is conditioned by a MPPT control system. This is the case of LISA Pathfinder, which solar array is composed of 39 strings of 24 cells each, for $650 \mathrm{~W}$ required power in EOL conditions. The nominal attitude during the mission is sun pointing, and the limited surface available for the solar array is due to mission and spacecraft configuration constraints. At a certain stage of the project it was decided to separate the solar panel from the rest of the structure by dedicated supports. This solution introduced the possibility to have different working temperatures between the strings and cells belonging to the same string, because of different thermal exchange modalities among centre and periphery of the panel.

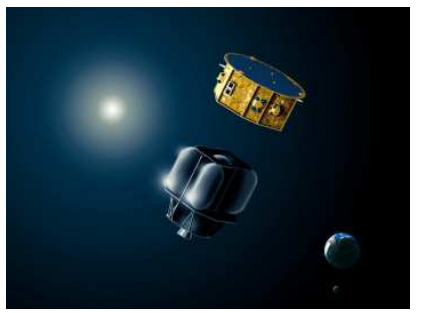

Fig. 25. LISA Pathfinder artistic impression

Therefore it was worth to analyse whether a temperature gradient of $30{ }^{\circ} \mathrm{C}$ between centre and periphery may originate knees in the I-V curve that may be recognised as false maximum power points by the MPPT control loop, leading to a block of the working point of the array in a non optimal position. Figure 26 shows the layout of the solar cells within their strings, adjacent rows of cells of the same colour belong to the same string. The resulting I-V curve (green) of the whole array is showed in figure 27, as term of comparison the two V-I curves calculated considering constant temperature are also reported as term of comparison. To be observed that the cell with the lowest temperature in a string rules the maximum current flowing trough the string itself. From the plot it can be concluded there are no knees between the open circuit voltage and the maximum power knee such to provoke the lock of the MPPT tracker around a false maximum power working condition. 


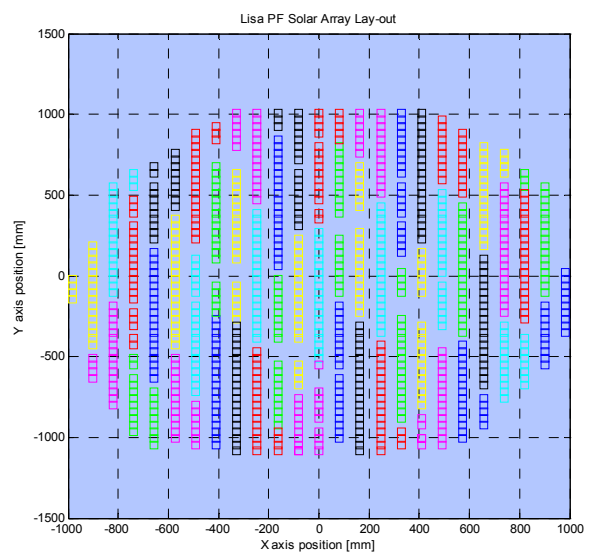

Fig. 26. Solar array layout

Figure 28 shows the illumination and the temperature reached by the solar panel in the first orbits after launch, the temperature over the panel is now considered as constant. It can be observed that the illumination takes into account also the contribution of the albedo just before and after an eclipse (no illumination), as expected from a solar panel always pointing towards to the sun throughout the orbit.

The figure 29 shows now the extended temperature profile over a period of 24 hours, together with output voltage and current; to be observed that from the fourth orbit onwards the temperature shows an slight increase after $70 \%$ of sunlight period has elapsed; this happens because when the battery is fully charged; the maximum power is not required anymore, the operating voltage of the array shifts toward the open circuit value. At the same time it can be seen that the output current decreases. This temperature increase is due to the difference between the maximum available power and the required one; the unused power warms up the array.

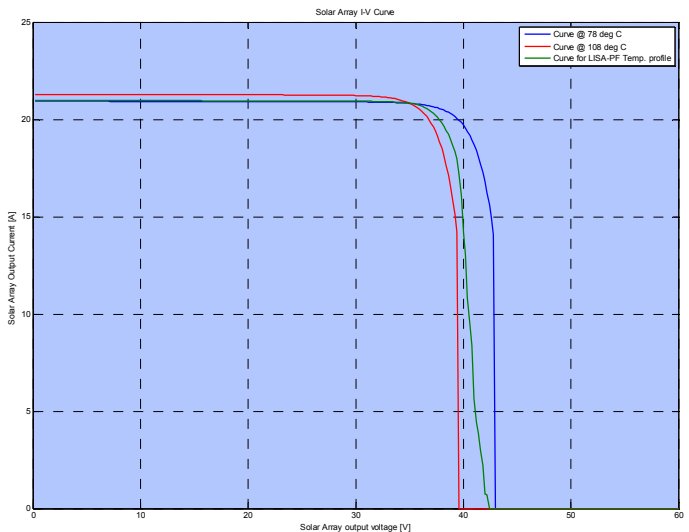

Fig. 27. LISA Pathfinder Solar array, V-I curve 


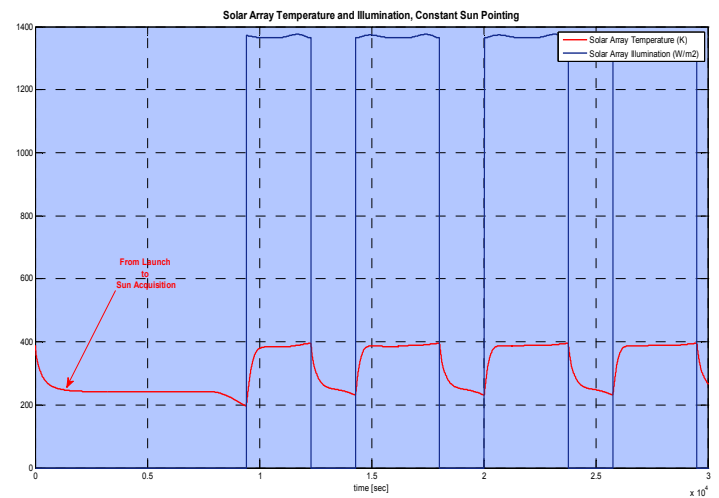

Fig. 28. Solar Array Illumination and temperature, launch phase and first 3 orbits

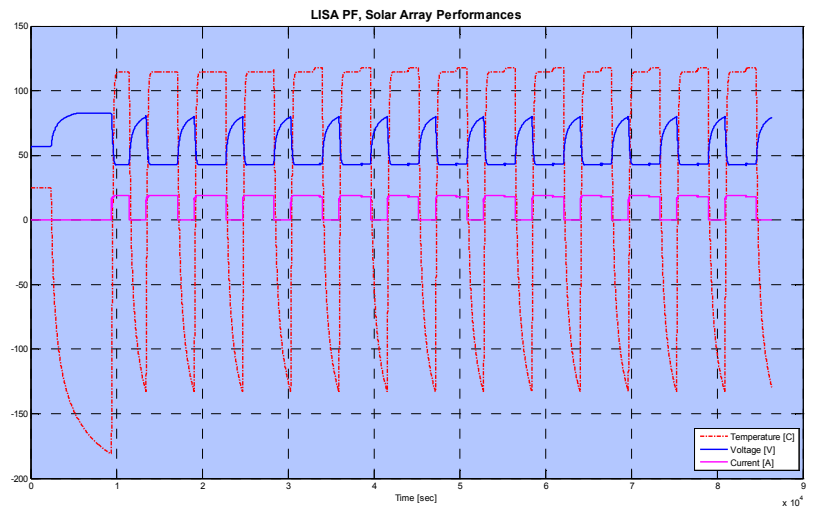

Fig. 29. Solar array temperature, output voltage and current

Finally, figure 30 shows the Depth Of Discharge (DOD \%) of the battery from launch. The DOD is progressively recovered the first four orbits. After the fourth one, a stable chargedischarge cycling is reached. 


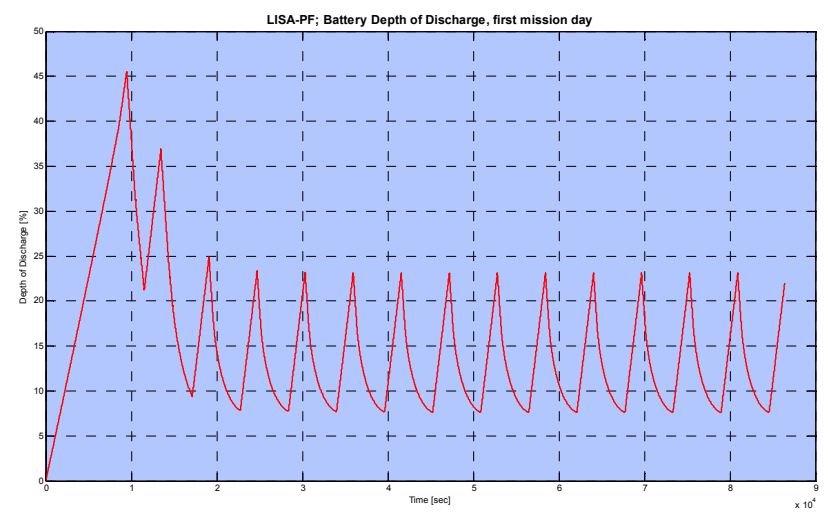

Fig. 30. Battery Depth of Discharge (DOD \%) for launch phase and first mission day.

\section{Conclusions}

Objective of this chapter was to provide guidelines for the design at system level of a solar array for satellites. Such kind of application has to be compliant with severe requirements mainly dictated by the harsh space environment mainly in terms of temperature levels, cosmic radiations which provoke wide variations of the performances together with their continuous degradation. Mass and size of the panels are main constraints with respect to the required power as well as optimal orientation towards to the sun, several times limited by other requirements at spacecraft and mission level. The actual state of the art is represented by triple junction solar cells capable to have a bulk efficiency of more than $30 \%$.

Typical accommodations of these arrays have been illustrated and a few design examples provided. These examples have been chosen among those may be considered as particularly challenging with respect to the required power and energy budgets coupled with mission constraints.

\section{References}

AZUR SPACE Solar Power GmbH, 3G-28\% Solar Cell Data-sheet http:/ /azurspace.de/index.php? $\mathrm{mm}=89$

Strobl, G. et al.; (2002). Advanced GaInP/Ga(In)As/Ge Triple junction Space Solar Cells, Proceedings of ESPC $20026^{\text {th }}$ European Space Power Conference, ESA-SP 502, Oporto, Portugal, May 2002.

Neugnot, N. et al.; (2008). Advanced Dynamic Modelling of Multi-junction Gallium Arsenide Solar Arrays, Proceedings of ESPC $20088^{\text {th }}$ European Space Power Conference, Konstanz, Germany, Sept. 2008.

Tada, H. and Carter, J., Solar Cell Radiation Handbook, JPL Report 77-56, Caltech, Pasadena, 1977

Mottet, S., Solar Cells Modelisation for Generator Computer Aided Design and Irradiation Degradation, ESA Symposium on Photovoltaic Generators in Space, pagg. 1-10, Heidelberg, 1980. 
Ferrante, J., Cornett, J. \& Leblanc, P., Power System Simulation for Low Orbit Space craft: the EBLOS Computer Program, ESA Journal Vol 6, 319-337, 1982.

Diffuse Surfaces, ESA PSS-03-108 Issue 1, 1989

O'Sullivan, A. Weinberg: The Sequential Switching Shunt Regulator (S3R); Proceedings Spacecraft Power Conditioning Seminar, ESA SP-126, 1977

Colombo, G., Grasselli, U., De Luca, A., Spizzichino, A., Falzini, S.; Satellite Power System Simulation, Acta Astronautica, Vol. 40, No. 1, pp 41-49, 1997.

De Luca, A. et al.; The LISA Pathfinder Power System, Proceedings of ESPC $20088^{\text {th }}$ European Space Power Conference, Konstanz, Germany, Sept. 2008.

De Luca, A., Chirulli, G.; Solar Array power Conditioning for a spinning satellite, Proceedings of ESPC $20088^{\text {th }}$ European Space Power Conference, Konstanz, Germany, Sept. 2008.

De Luca. A.; Simulation of the Power System of a Satellite, graduation thesis, ESA EAD (European Aerospace Database),Quest Accession Number 96U03072, 1996. or Database NASA, Quest Accession Number 96N48163, 1996. 


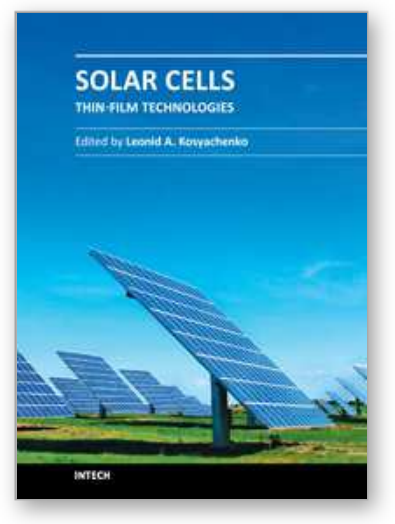

\author{
Solar Cells - Thin-Film Technologies \\ Edited by Prof. Leonid A. Kosyachenko
}

ISBN 978-953-307-570-9

Hard cover, 456 pages

Publisher InTech

Published online 02, November, 2011

Published in print edition November, 2011

The first book of this four-volume edition is dedicated to one of the most promising areas of photovoltaics, which has already reached a large-scale production of the second-generation thin-film solar modules and has resulted in building the powerful solar plants in several countries around the world. Thin-film technologies using direct-gap semiconductors such as CIGS and CdTe offer the lowest manufacturing costs and are becoming more prevalent in the industry allowing to improve manufacturability of the production at significantly larger scales than for wafer or ribbon Si modules. It is only a matter of time before thin films like CIGS and CdTe will replace wafer-based silicon solar cells as the dominant photovoltaic technology. Photoelectric efficiency of thin-film solar modules is still far from the theoretical limit. The scientific and technological problems of increasing this key parameter of the solar cell are discussed in several chapters of this volume.

\title{
How to reference
}

In order to correctly reference this scholarly work, feel free to copy and paste the following:

Antonio De Luca (2011). Architectural Design Criteria for Spacecraft Solar Arrays, Solar Cells - Thin-Film Technologies, Prof. Leonid A. Kosyachenko (Ed.), ISBN: 978-953-307-570-9, InTech, Available from: http://www.intechopen.com/books/solar-cells-thin-film-technologies/architectural-design-criteria-for-spacecraftsolar-arrays

\section{INTECH}

open science | open minds

\author{
InTech Europe \\ University Campus STeP Ri \\ Slavka Krautzeka 83/A \\ 51000 Rijeka, Croatia \\ Phone: +385 (51) 770447 \\ Fax: +385 (51) 686166 \\ www.intechopen.com
}

\author{
InTech China \\ Unit 405, Office Block, Hotel Equatorial Shanghai \\ No.65, Yan An Road (West), Shanghai, 200040, China \\ 中国上海市延安西路65号上海国际贵都大饭店办公楼405单元 \\ Phone: +86-21-62489820 \\ Fax: +86-21-62489821
}


(C) 2011 The Author(s). Licensee IntechOpen. This is an open access article distributed under the terms of the Creative Commons Attribution 3.0 License, which permits unrestricted use, distribution, and reproduction in any medium, provided the original work is properly cited. 